\title{
Sale of monopoly information and behavior of rivaling clients: A theoretical perspective
}

\author{
Chun-Hao Chang ${ }^{\mathrm{a}, *}$, Arun J. Prakash ${ }^{\mathrm{a}}$, Shu Yeh ${ }^{\mathrm{b}}$ \\ ${ }^{a}$ Department of Finance, Florida International University, University Park, Miami, FL 33199, USA \\ ${ }^{\mathrm{b}}$ National Taiwan University, Taiwan
}

Received 16 July 2002; received in revised form 9 March 2003; accepted 4 November 2003

Available online 8 January 2004

\begin{abstract}
This paper studies a three-stage Bayesian-Cournot game where rivaling firms sign contracts with an information monopoly to purchase proprietary information. The rivaling firms use the external information to create competitive advantage over one another. Knowing the rivalry among its clients, the information monopoly can exploit them by playing one client against another. The information-selling strategy depends on the clients' inhouse information technology, the uncertainty of the economic environment, and the number of potential clients. The existence of an information market makes rivaling producers worse off and consumers better off. It is possible that the service of the information monopoly is a private good but a social bad.
\end{abstract}

(C) 2003 Elsevier Inc. All rights reserved.

JEL classification: C7; D4; D8

Keywords: Bayesian-Cournot game; Oligopoly; Strategy-enhancing effect

\section{Introduction}

The advancement of electronic data processing technology, the increasing sophistication in statistical and economic analysis, and the globalizations of business operation all contribute to the rapid growth of the marketing research industry. ${ }^{1}$ A marketing research firm, as a specialist in collecting and processing market intelligence, does not have a comparative advantage in the actual productive utilization of its market intelligence. On the other hand, production firms, which specialized in the manufacturing of end products but do not have the expertise or scale economy to generate precise market intelligence, are

* Corresponding author. Tel.: +1-305-348-2845; fax: +1-305-348-4245.

E-mail address: changch@fiu.edu (C.-H. Chang).

${ }^{1}$ Honomichl (1989) reports an aggregate sales of 2.6 billion for the top 50 marketing research firms alone in 1988. 
willing to acquire the proprietary information from the market researchers to assist their production planning and enhance their competitive advantages. The connection and interaction between the information and product markets are important features of a modern economy. However, very little attention has been paid to this area.

This paper studies the interaction between the information and product markets. We focus our attention on a circumstance that a monopolistic market research firm (or an information monopolist) provides proprietary information about the industry demand to its oligopolistic production clients. In our model, the total industry demand is unknown to all the production firms because it is subject to uncertain factors such as geopolitical uncertainties, weather, energy prices, etc. These uncertain factors are summarized as a stochastic shock to the industry demand. A positive (negative) stochastic shock will result in a higher (lower) industry demand. The product market competition involves firms making strategic production decisions under the demand uncertainty. The product market competition is characterized by a Bayesian-Cournot equilibrium.

Under the demand uncertainty, the firms have an incentive to acquire information from the market research firm to better predict the total market demand and, hence, improve their competitive positions. As a result, the pricing strategy of the information monopolist is nontrivial because the demand for information in the information market is a derived demand from the strategic behaviors of the firms in the product market. In addition to the option of purchasing market information from the market research firm, we allow each production firm to conduct in-house market research. ${ }^{2}$ Consequently, the value of the market research firm's information to a production firm depends not only on the number of rivaling firms acquiring the information but also on the quality of the competing firms' in-house market research technologies.

In the information market, we examine a simple construct - an information monopoly. ${ }^{3}$ The monopolistic nature of the information market arises from a high fixed cost for collecting and processing proprietary information and a negligible marginal cost for reproducing information. ${ }^{4}$ The behavior of an information monopoly selling information to traders in a financial securities market has been examined by Admati and Pfleiderer $(1986,1990)$. A special feature in their model is the information externality (or the "public good" effect referred in Hirshleifer and Riley, 1992 $2^{5}$ arising from the rational expectations equilibrium in financial markets. The equilibrium price of financial securities conveys part of the

${ }^{2}$ In reality, given the existence of independent market research firms, production firms still conduct their own in-house market research. For example, almost all major brand pharmaceutical companies have their own in-house market research department, and they also purchase proprietary market information from IMS International.

3 An example of a monopolistic marketing information market is the IMS International, a research firm that processes and sells international sales data on prescription and over-the-counter drugs and worldwide information on physicians' prescription activities.

${ }^{4}$ If both the fixed cost and marginal cost of information are negligible, the information market is perfectly competitive. A typical research firm in the competitive market usually provides services, such as focus group moderating and facilities; primary data collection using mail or telephone surveys; and full-service marketing research, including data processing and analysis. There are more than 10,000 independent, perfectly competitive marketing research consultants listed in McLean (1990). In addition, we also observe oligopolistic research firms providing similar but differentiated high-cost information. For example, A.C. Nielsen, IRI, and SAMI all supply differentiated panel data for the packaged good industry. Additional discussion of the information service industry may be found in Chang and Lee (1994).

5 Hirshleifer and Riley (1992, chap. 7) gives a comprehensive discussion on the various forces affecting the production of information. The "public good" effect, which arises from the free-rider problem of information, may induce underinvestment in information production. 
information possessed by the informed traders, and the uninformed traders may free-ride on the information. Inasmuch as the value of information depends on this information externality, the monopolistic information seller may have an incentive not to add noise to the information before selling or to sell the information indirectly through selling shares of a fund portfolio under its management.

On the other hand, the "public good" effect does not exist in our model because of the strategic rivalry among oligopolistic production firms. In a product market, the equilibrium price is determined after the production process is completed. Therefore, the uninformed firms cannot free-ride on the private information of the informed firms.

The strategic use of information in oligopoly has been extensively studied in the literature. ${ }^{6}$ Novshek and Sonnenschein (1982) have pioneered a line of research dealing with sharing of exogenously given information among Cournot oligopolists. Their followers include Clarke (1983), Fried (1984), Gal-Or (1985), Jin (1994), Kao and Hugres (1993), Li (1985), Shapiro (1986), and Vives (1984). A typical model in this line of research is a two-stage Bayesian-Cournot game. In the first stage, firms decide whether to pool their exogenously given information (in the form of a signal) ex ante (before the signals are realized). In the second stage where all the signals are realized, the firms make an ex post decision on production quantity. The exogenously given signals may be either about the uncertain industry demand (see, e.g., Clarke, 1983; Gal-Or, 1985; Li, 1985; Novshek \& Sonnenschein, 1982; Vives, 1984) or about the uncertain production costs (see, e.g., Fried, 1984; Li, 1985; Shapiro, 1986). The general results in these models are (a) when uncertainty is about private costs, perfect information sharing is the unique equilibrium; and (b) when uncertainty is about the common industry demand, sharing no information is the only solution. In addition, Jin (2000) and Raith (1996) generalize the information sharing results to a large class of oligopolistic models. Some of the empirical and experimental studies on information sharing games in oligopoly can be found in Cason and Mason (1999) and Doyle and Snyder (1999). The abovementioned results are generally verified.

One limitation in the information sharing literature is that the information is exogenously given, not strategically acquired by the firms. Chang and Lee (1992, 1994), Hwang (1993), and Li, McKelvey, and Page (1987) modify the two-stage information sharing games to allow firms to engage in endogenous information acquisition activities. In the first stage of the game, each firm selects a level of information acquisition, which is measured by the precision of the information service. The higher the precision, the more precise the information signal will be received in the second stage of the game, where the output decisions will be made. Li et al. obtain symmetric information acquisition results by assuming all firms are identical. Chang and Lee secure asymmetric results by assuming differentiated products and firm-specific information. They demonstrate how the firms use information acquisition as business strategy to gain a competitive edge. Hwang derives the equilibrium information acquisition in competitive, oligopoly, and monopoly markets, and compares the equilibrium expected welfare levels. In addition, Vives (1988) examines the information aggregation in an oligopoly, while Ziv (1993) studies the incentive for firms to send misleading information signals in information sharing games.

\footnotetext{
${ }^{6}$ An early analysis of the information game in oligopoly can be found in Ponssard (1976, 1979). The concept of BayesianNash equilibrium was introduced in Harsanyi (1967). Ponssard studies a case in which $n$ Cournot oligopolistic firms face a stochastic demand curve and only $k$ firms out of the total $n$ firms are informed with the true demand. He established a unique Bayesian-Cournot equilibrium for each $k$ and demonstrates that the value of information decreases with the number of the informed.
} 
In this paper, we extend the conventional two-stage Bayesian Cournot model by adding a third stage game to depict the information selling by the information monopolist. This extra stage in the model provides a linkage between the product and the information markets. We assume that rivaling production firms are identical in production technology as well as their in-house information acquisition technology. This symmetry assumption helps us simplify the analytical results without loss of generality. ${ }^{7}$ In addition, each producer can purchase the proprietary information from the information monopolist to improve its marketing judgement, production decision, and competitive advantage. The rivaling producers use the information strategically against each other. Knowing the rivalry among its clients, the information monopolist can exploit them by playing one client against another. The purpose of this paper is to understand the interaction between the monopolistic information market and the oligopolistic product market, the equilibrium of the whole economy, and the welfare implications of the information monopoly.

The first two stages of the game involve the activities in the information market and can be described as a Stackelberg game. In the first stage, the information seller sets the information price to maximize its profit against the reaction functions of all production firms. In the second stage, each production firm can sign a contract with the information seller as a price taker. The third stage of the game involves the activities in the product market. As the stochastic shock is realized, every agent receives a private signal. The information seller reveals its proprietary information to contracted clients. All production firms choose, conditional on their information, output quantities independently and simultaneously to maximize their expected profits. ${ }^{8}$

In this paper, we derive a unique Bayesian-Cournot equilibrium for the three-stage game. One innovative feature of this paper is that we allow the production firms to produce noisy information based on their in-house information technology. The information selling strategy of the information monopolist depends on its clients' information technology, the uncertainty of economic environment, and the number of potential clients. Our analysis demonstrates that an information monopoly would discriminate its clients by denying service to some of them even when all its clients were identical. The demand for information contracts is downward sloping, and hence, the equilibrium price of information is inversely related to the number of contracts rationed among rivaling clients.

The information monopolist's equilibrium information selling strategy also depends on the production firm's in-house information technology. When all its potential clients have relatively primitive information technology, the information monopolist would ally with only one producer by providing the favored client the "exclusivity"; they then jointly exploit everyone else. Inasmuch as the information seller could ally with anyone it chooses, it ends up pocketing all the economic rent. To strategically exploit its rivaling clients, when the number of potential clients is more than two, the information seller would never want to sell its information to everyone. Furthermore, we show that the existence of information market makes rivaling producers worse off and atomistic consumers better off. When all producers have relatively advanced information technology, the information monopolist is better off providing information to more

\footnotetext{
7 An interesting extension to our model, as suggested by an anonymous referee, is allowing the production firms to produce in-house information only if they choose not to pay the price asked by the information monopolist for its information or if the monopolist refuses to sell. We will leave this for future research.

8 The three-stage game structure is very similar to that of Kamien and Tauman (1986) and Katz and Shapiro (1986). These authors model a three-stage game in which an independent research lab develops and licenses a cost reducing innovation to competing Cournot firms. There is no uncertainty on the innovative technology in these models, and the game structures are of complete information, which may be considered as a special case of the model in this paper.
} 
than one client. Under certain conditions, it is optimal for the information monopolist to sell to all but one production firm.

The rest of this paper is arranged as follows. Section 2 describes the model. Section 3 solves the Bayesian-Cournot game to derive the equilibrium conditions for the product market and the information market. The strategy of selling proprietary information to rivaling clients is also analyzed. Section 4 discusses the welfare issues. Concluding remarks then follow. Proofs are in Appendix A, and a more general model with asymmetric information technology is discussed in Appendix B.

\section{The model}

\subsection{The economy}

The economy consists of three types of agents: a monopolistic information seller, $n$ rivaling producers, and numerous consumers. The economy has two markets: an information market and a product market. The decision sequences of the agents in both markets are illustrated in Table 1 .

In the information market, the information seller makes Decision I by setting the information price $\alpha$. As a consequence of firms' optimizing behavior in Stage III, the demand function for information contracts is inversely related to the number of firms that sign the information contracts. The information seller simultaneously determines the information price and the number of information contracts, denoted by $k$. The information seller then tenders $k$ take-it-or-leave-it offers to clients. We assume that the information seller has a good reputation to precommit itself selling $k$ and only $k$ contracts. Thus, the announcement of $\alpha$ in public is believed by all participants in the game. ${ }^{9}$ In Decision II, the production firm, being offered the contract, considers whether to accept or reject it. ${ }^{10}$

The rivaling producers can be divided into two groups as a result of the information selling game: $k$ "informed" firms and $(n-k)$ "uninformed" firms. Both the informed and uninformed are able to collect their private information, but the informed receives additional information from the information seller. In Decision III, $k$ informed firms and the $(n-k)$ uninformed firms engage in a Bayesian-Cournot game where each firm uses quantity as decision variables conditioned on the information each firm has. In Decision IV, the consumers act passively. They act as price takers and choose their demand quantity according to the market price $P$. The solution to the whole game is a subgame perfect Bayesian-Cournot equilibrium. Therefore, the whole game is solved by backward induction.

\subsection{The consumer}

The consumer's behavior can be described by a linear inverse demand curve. The demand function is uncertain in the sense that it is subject to a level stochastic shock. The realization of a stochastic

\footnotetext{
9 If the information selling is a one-shot event, the information seller will have an incentive to renegotiate with the remainder of the potential clients after all $k$ contracts have been sold. The $k$ original clients will suffer a loss because the value of their purchased information declines as a result of this side contract. If the information game will be played repeatedly, the information seller is well motivated to restrict its information contracts to no more than a precommitted number to maintain its reputation. Naturally, clients can assure the precommitment by the court enforcement.

10 The take-it-or-leave-it offer is the simplest form of bargaining-assuming that the information seller has all the bargaining power. The qualitative property of our results will not change if another form of bargaining solution is used.
} 
Table 1

Agents' decisions in the information market and the product market

\begin{tabular}{llll}
\hline Information market & & Product market & \\
\hline $\begin{array}{l}\text { Decision I } \\
\text { Information } \\
\text { seller }\end{array}$ & $\begin{array}{l}\text { Decision II } \\
\text { Production firms }\end{array}$ & $\begin{array}{l}\text { Decision III } \\
\text { Production firms }\end{array}$ & $\begin{array}{l}\text { Decision IV } \\
\text { Consumers }\end{array}$ \\
$\begin{array}{l}\text { Monopoly } \\
\text { Making take-it- }\end{array}$ & Oligopsony & Oligopoly & Atomistic \\
$\begin{array}{l}\text { or-leave-it } \\
\text { information }\end{array}$ & Choosing to accept or & Receiving & Passive with no \\
contracts with & reject the information & information signals & strategic consideration; \\
rivaling producers & contract & Bayesian-Cournot & choosing demand at \\
\end{tabular}

shock causes a change in the intercept of the demand function or a parallel shift of the demand function. A positive (negative) shock implies a higher (lower) industry-wide demand. Let $\theta$ be the random shock, $\theta \in \Theta$, where $\Theta$ is the set of all the possible random shocks; then the stochastic demand function is

$$
P=a+\theta-b Q
$$

where $a$ and $b$ are positive constants, $P$ is the price of the product, and $Q$ is the aggregate quantity sold. The linearity assumption is standard in the literature.

\subsection{Production firms}

The supply side of the product market includes $n$ rivaling firms that produce a homogeneous product with the same constant return to scale technology. Without loss of generality, the constant marginal cost is normalized to zero. Firms are assumed to maximize expected profits using quantity as their decision variable.

No firm is able to observe the state of the nature ex ante. Instead, firms share a common prior assessment on $\theta$. This prior assessment is represented by a prior probability distribution of $\theta$, denoted by $G(\theta)$, which has zero mean and nonzero precision $R=1 / \operatorname{VAR}(\theta)$. The parameter $R$ can be interpreted as the perceived environment uncertainty, where a high value of $R$ will indicate a low level of perceived environment uncertainty.

To update the prior assessment, each firm sets up an in-house research unit to observe a noisy signal, $y_{i}$, about the state of nature. We assume that $y_{i}$ is generated by an information technology that can be specified as a conditional probability distribution $g\left(y_{i} \mid \theta\right)$ with $t_{i}=1 / \operatorname{VAR}\left(y_{i} \mid \theta\right)$ as the precision of the private signal. The value of $t_{i}$ indicates the quality or the precision of information technology. That is, the private signal $y_{i}$ is an estimate of $\theta$. Each firm then utilizes its private signal to estimate the industry demand and plan its production strategy accordingly. The accuracy of $y_{i}$ depends on the quality of the firm's in-house information technology. To the extreme, if $t_{i}=\infty$ then $y_{i}=\theta$, the firm would be able to receive a noiseless signal and thus observe the true industry demand. Without loss of generality, we 
assume that firms are identical in information technology, that is, $t_{1}=t_{2}=t_{3}=\ldots=t_{n}=t<\infty$ to simplify our analysis. ${ }^{11}$

Following Li (1985), the information system is assumed to emulate the linear conditional expectation assumptions:

Assumption 1. $E\left[y_{i} \mid \theta\right]=\theta, \forall i$.

Assumption 2. $y_{i}$ is independent of $y_{j}$, conditional on $\theta, \forall i \neq j$.

Assumption 3. $E\left[\theta \mid y_{i}\right]=\gamma_{i}+\delta_{i} y_{i}, \forall i$, where $\gamma_{i}$ and $\delta_{i}$ are constants.

Assumption 1 implies that the signal each firm receives is an unbiased estimator of the true state of the world, $\theta$, hence only the precision of the signal, not the signal itself, matters. Assumption 2 indicates that each firm conducts its in-house research independently and secretly, thus, no cooperative behavior is allowed. Assumption 3 imposes linearity on conditional expectations. This assumption holds if the underlying probability distributions of the signals are normal-normal, beta-binomial, or gammapoisson (see DeGroot, 1970, for detail). The following results are direct consequences using Assumptions $1-3$.

$$
\begin{aligned}
& \gamma_{i}=\left(1-\delta_{i}\right) E(\theta)=0 \\
& \delta_{i}=\frac{\operatorname{VAR}(\theta)}{\operatorname{VAR}\left(y_{i}\right)}=\frac{\operatorname{VAR}(\theta)}{\left\{\operatorname{VAR}(\theta)+E\left[\operatorname{VAR}\left(y_{i} \mid \theta\right)\right]\right\}}=\frac{t_{i}}{\left(t_{i}+R\right)} \\
& E\left(y_{j} \mid y_{i}\right)=E\left(\theta \mid y_{i}\right)=\frac{y_{i} t_{i}}{\left(t_{i}+R\right)}, \forall j \neq i \\
& \operatorname{VAR}\left(y_{i}\right)=\frac{1}{R}+\frac{1}{t_{i}}, \\
& \operatorname{COV}\left(\theta, y_{i}\right)=\operatorname{COV}\left(y_{i}, y_{j}\right)=\operatorname{VAR}(\theta)=\frac{1}{R} .
\end{aligned}
$$

These results describe how a firm uses its private signal to infer the state of nature and its opponent's signal. The first result in Eq. (2) indicates that the intercept term $\gamma_{i}$ in Assumption 3 is zero. This implies that the conditional expectations of firm $i$ with respect to the state of the world, $\theta$, is proportional to the private signal the firm received and is expressed as $\delta_{i} y_{i}$. The second result in Eq. (2) expresses $\delta_{i}$ as a function of $t_{i}$ (the precision of in-house information technology) and $R$ (the precision of the prior distribution). The symbols $t_{i}$ and $\delta_{i}$ can be respectively interpreted as the absolute and relative precision of signal $y_{i}$, and $t_{i}$ measures the quality of the in-house research

\footnotetext{
11 A more general model with asymmetric information technology is discussed in Appendix B.
} 
department for firm $i$. In general, a higher $t_{i}$ indicates less noise in $y_{i}$ so the firm can better predict the true industry demand. However, it is more meaningful to describe the quality of in-house information by using the relative precision $\delta_{i}$. If the prior distribution has a very small variance $(R$ is very large, and $\delta_{i}$ is close to zero), that is, the industry demand is of very low uncertainty, the relative importance of an in-house research department would be less. The predicting power of the firm's private signal is relatively low.

The third result in Eq. (2) shows that a firm's conditional expectations (based on its own information signal) of its opponent's private signal, $y_{j}$, is the same as its conditional expectations of the state of the world, $\theta$. This result is again a direct consequence of the assumed linear information structure. Finally, we also assume that the prior distribution $\mathrm{G}(\cdot)$, the conditional distribution $\mathrm{g}(\cdot \mid \cdot)$, and the whole information system are common knowledge to all agents.

The rivaling producers also comprise the demand side of the information market. Each producer will accept the take-it-or-leave-it information contract if the value of information is no less than the information price offered and will reject the contract if otherwise. ${ }^{12}$ Inasmuch as the purchased information is used for plotting strategy against one's rivals in the product market, the information purchase decision of firm $i, \tau_{i}$, depends on the number of rivals that have access to the same information $(k)$. We set $\tau_{i}(k)$ as a characteristic function such that

$$
\tau_{i}(k)= \begin{cases}1, & \text { if } i \text { purchases the contract } \\ 0, & \text { if } i \text { does otherwise. }\end{cases}
$$

\subsection{The information seller}

The information market is a natural monopoly inasmuch as the information seller usually puts up a large initial investment but spends a trivial marginal cost for serving additional clients. For simplicity, the information seller's information technology is assumed to be perfect. ${ }^{13}$ The information selling strategy is to choose an information price $\alpha$ that maximizes its profits. Once $\alpha$ is decided, the target number of information contracts is also determined. The information seller then makes take-it-orleave-it offers to all production firms. The information seller's total profit is $k \alpha$ net of information costs.

\section{Equilibrium}

The whole game is solved by backward induction. We first derive the equilibrium in the product market and then the equilibrium of the information market.

\footnotetext{
12 Without loss of generality, we assume that the firm accepts the offer if it feels indifferent about it (i.e., the value of information equals the information price).

13 The information seller has complete information about the true state of nature and provides noiseless signal to its clients. This assumption simplifies our presentation. Most of our results do not depend on this assumption.
} 


\subsection{Product market equilibrium}

The product market has two types of producers: $k$ informed firms who accepted the information contract and $(n-k)$ uninformed who either rejected the information contract or were not offered the contract. In the beginning of this stage of the game, all the random variables, $\left(\theta, y_{1}, y_{2}, \cdots, y_{n}\right)$, are realized. The informed firm observes two signals: a private signal $y_{i}$ and a purchased signal $\theta$. Inasmuch as $\theta$ is a perfect (noiseless) signal, its purchase renders the private signal redundant. The uninformed firm observes only its own private signal. These $k$ informed firms and $(n-k)$ uninformed firms engage in a BayesianCournot game. Each firm forms Bayesian estimates about the state of nature as well as its rivals' signals.

The solution to this Bayesian-Cournot game is well documented in the literature (see, e.g., Proposition 1 of $\mathrm{Li}$ et al., 1987). In our application, given $k, \theta$, and $y=\left(y_{1}, y_{2}, \cdots, y_{n}\right)$, there exists a unique equilibrium with the following equilibrium strategy

$$
q_{i}^{*}= \begin{cases}\frac{a}{(n+1) b}+\frac{1}{[(n+1) t+2 R(k+1)] b}(t+2 R) \theta, & \text { if } \tau_{i}=1, \\ \frac{a}{(n+1) b}+\frac{1}{[(n+1) t+2 R(k+1)] b}(t) y_{i}, & \text { if } \tau_{i}=0 .\end{cases}
$$

Thus, a firm's equilibrium quantity is linear in its signal: linear in $\theta$ for informed firms and linear in $y_{i}$ for uninformed. In Eq. (4), we also notice the difference in production strategies between the informed and the uninformed firms: the informed firms will make their production quantity based on the factor $(t+2 R)$ while the equilibrium output for the uninformed will be based on factor $t$. Inasmuch as $(t+2 R)>t$, we observe that the informed firm, knowing that the signal it received is precise, produces a quantity that is more responsive to its signal. If both the informed and the uninformed firms receive the same positive (negative) signal, one can see that the informed firms produce more (less) than the uninformed in equilibrium by a factor mainly depend on the quality of information, measured by the precision of the prior distribution $R$. As we have a large value of $R$, that is, the quality of the information is high, the advantage of being informed is great, the informed firms would produce more (less) if the demand is high (low) with a positive (negative) shock. The product market equilibrium price is determined by Eqs. (1) and (4).

\subsection{Information market equilibrium—production firms' view}

In Decision II, the payoff function of each production firm is the ex ante expected profit function net of the cost of purchased information. The ex ante expected profit depends on the information technology $t$, the information price $\alpha$ and thus the target number of information contract $k$, and the firm's in-house information decision $\tau_{i}$. Let $\Pi_{i}\left(k, \tau_{i}\right)$ be firm $i$ 's ex ante expected profit function, and $\Pi_{i}\left(k, \tau_{i}, \theta, y\right)$ be the ex post profit function conditional on the realization of signals, then it is straightforward to compute the payoff of information decision $\Pi_{i}$ as

$$
\Pi_{i}\left(k, \tau_{i}\right)= \begin{cases}E\left[E\left(\Pi_{i} \mid \theta\right)\right], & \text { if } \tau_{i}=1, \\ E\left[E\left(\Pi_{i} \mid y_{i}\right)\right], & \text { if } \tau_{i}=0\end{cases}
$$




$$
\begin{aligned}
& \Pi_{i}(k, 1)=\frac{a^{2}}{(n+1)^{2} b}+\frac{(t+2 R)^{2}}{[(n+1) t+2 R(k+1)]^{2} b R} \\
& \Pi_{i}(k, 0)=\frac{a^{2}}{(n+1)^{2} b}+\frac{t(t+R)}{[(n+1) t+2 R(k+1)]^{2} b R}
\end{aligned}
$$

The information selling game progresses sequentially; the information seller will not stop until all the announced contracts are sold. Each producer knows that there will be $k$ contracts sold regardless of its own in-house information decision. Hence, firm $i$ 's value of information (i.e., the reservation price on the information contract), $v_{i}(k)$, is the difference in ex ante expected profits as a result of the information purchase:

$$
\begin{aligned}
v_{i}(k) & =\Pi_{i}(k, 1)-\Pi_{i}(k, 0) \\
& =\frac{3 t+4 R}{[(n+1) t+2 R(k+1)]^{2} b} .
\end{aligned}
$$

By symmetry, $v_{i}(k)=v(k), \forall i$. Eq. (6) gives rise to the following properties of $v(k)$ :

Lemma 1. The value of purchased information, $v(k)$, decreases as

(i) the number of clients $k$ increases;

(ii) the number of rivaling producers $n$ increases;

(iii) the producers' information technology t improves.

The effect of perceived environment uncertainty $(R)$ on the value of purchase information is ambiguous.

Information purchase can improve a producer's expected profit in two ways: (1) an uncertainty reduction effect and (2) a strategy enhancing effect. The uncertainty reduction effect improves the precision of production decision. The strategy enhancing effect strengthens a producer's competitive advantage against its rivals. The uncertainty reduction effect is a direct effect and is independent of the market structure. The strategy enhancing effect is an indirect effect arising from the interaction among rivals in the product market. ${ }^{14}$

As more information contracts are sold and more firms become informed, the purchased information becomes less useful for gaining competitive advantage. The marginal benefit of being an information holder decreases. Hence, the demand for information contracts is a strictly downward sloping curve: the firm is willing to pay a high price when only a few information contracts are available.

When the number of firms in an oligopoly gets larger, the level of externality from each firm's decision gets smaller. Hence, the strategy-enhancing effect of information purchase becomes smaller and

14 Chang and Lee (1992) provide another interesting analysis of these two effects of information acquisition in an oligopoly. They show that a firm can improve its decision precision and competitive advantage by strengthening the capability of its inhouse marketing research department. 
the value of the purchased information becomes lower. As each firm's information technology gets more advanced, the value of purchased information should decline.

Generally, a reduction in the perceived environment uncertainty (i.e., an increase in the precision of prior assessment $R$ ) has two effects. On one hand, the reduction of perceived environment uncertainty reduces the value of all information, including the purchased information. On the other hand, it makes the relative quality of a given firm's in-house information technology $(t / R)$ lower and makes the purchased information (which is perfect) relatively more attractive. Hence, the effect of a change in the perceived environment uncertainty on the value of purchased information is ambiguous.

The value of purchased information can be calculated from Eqs. (5) and (6) for all $k<n$ but not for $k=n$. In fact, the value of purchased information in Eq. (6) is not well defined for the case of $k=n$. When $k=n$ and firm $i$ rejects the information contract, then only $(n-1)$ contracts can be sold in the information market. Therefore, we define $\hat{v}(n)$ as

$$
\begin{aligned}
\hat{v}(n) & =\Pi_{i}(n, 1)-\Pi_{i}(n-1,0) \\
& =\frac{(3 n-1)(n+1) t+4 n^{2} R}{(n+1)^{2}[(n+1) t+2 n R]^{2} b} .
\end{aligned}
$$

Information strategy for firm $i$ is based on Eqs. (3) and (6). Recall that $\alpha$ is the offer price of the information contract. The firm's information acquisition strategy is

$$
\tau_{i}^{*}(k)= \begin{cases}1, & \text { if } v(k) \geq \alpha, \\ 0, & \text { if } v(k)<\alpha .\end{cases}
$$

\subsection{Information market equilibrium: the information seller's view}

The information seller selects the price of the contract, $\alpha$, given the potential clients' strategies in the subsequent decisions. ${ }^{15}$ The target number of contracts, $k$, can be endogenously determined subsequently. Proposition 1 summarizes the information seller's optimal strategy.

Proposition 1. When the number of potential clients is larger than two ( $n>2)$, the information seller would never want to sell information to everyone. ${ }^{16}$ The unique optimal strategy for the information seller is

$$
\begin{cases}k^{*}=1+\frac{(n+1) t}{2 R} \text { and } \alpha^{*}\left(k^{*}\right)=v\left(k^{*}\right), & \text { if } \frac{t}{R}<\frac{2(n-2)}{n+1} \\ k^{*}=(n-1) \text { and } \alpha^{*}(n-1)=v(n-1), & \text { otherwise. }\end{cases}
$$

\footnotetext{
15 In this study, we focus on the uniform-price contract which is the dominant pricing scheme in practice. In theory, it is possible for the information seller to make more profit using the following strategy: the information monopolist commits to a take-it-or-leave-it offer exclusively to firm $i$ at a price $\Pi(1,1)-\Pi(n-1,0)-\epsilon$, with a clause stating that in the event firm $i$ declines, the information monopolist may have higher profit under some conditions than $k^{*} v\left(k^{*}\right)$.

16 When $n=2$, the information is sold to both producers if $t / R \geq 4 / 3$ and sold to one producer if $t / R<4 / 3$. Hence, when the information seller faces two relatively well-informed clients, she may sell information to both firms.
} 


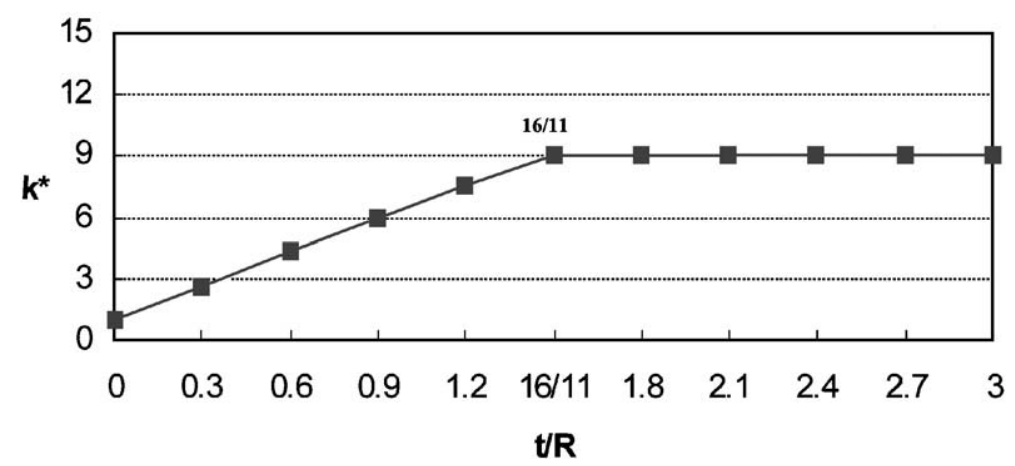

Fig. 1. Number of contracts sold.

The maximum profit (net of information costs) for the information seller is

$$
\left\{\begin{array}{l}
k^{*} v\left(k^{*}\right)=\frac{3 t+4 R}{8[(n+1) t+2 R] b R}, \quad \text { if } \frac{t}{R}<\frac{2(n-2)}{n+1} \\
(n-1) v(n-1)=\frac{(n-1)(3 t+4 R)}{[(n+1) t+2 n R]^{2} b}, \text { emotherwise. }
\end{array}\right.
$$

The uniqueness of optimal strategy in Proposition 1 is a direct consequence of the (strictly) downward sloping information demand curve as stated in Lemma 1.

In Proposition 1 , it is clear that the optimal strategy for the information monopolist, $k^{*}$, depends on the relative information precision $(t / R)$. Fig. 1 illustrates the relationship between $k^{*}$ and $(t / R)$. The information seller's strategy on $k^{*}$ can influence the strategy-enhancing effect of its information but has nothing to do with the uncertainty reduction effect.

When all the rivaling producers have better information technology, the strategic enhancing effect of the purchased information declines. The strategic enhancing effect arises from the fact that the information seller can help its clients to gain competitive advantage over other producers by making its information available to some but not to others. Then the information seller and its clients can share this economic rent. ${ }^{17}$ When the rivaling clients cannot use the purchased information to gain competitive advantage over one another, the information seller cannot exploit extra profits by selling only to a few of its clients. Hence, as the clients' in-house information technology gets more sophisticated, the information seller makes its service more widely accessible.

In Fig. 1, we consider a case of 10 production firms. When all producers are completely ignorant [i.e., $(t / R)=0$ ], whoever gets the purchased information will dominate the product market. Hence, it is an optimal strategy for the information seller to ally with only one client; they then jointly exploit everyone else. Inasmuch as the information seller can ally with anyone, it ends up pocketing all of the economic exploitation. As producers improve their information technology or as the perceived environment uncertainty gets lower [i.e., $(t / R)$ becomes larger], the optimal number of contracts, $k^{*}$, increases as a linear function of $(t / R)$ with the slope of $(n+1) / 2=5.5$. Eventually, as $(t / R)$ reaches above the value of

\footnotetext{
17 Inasmuch as the information seller is a monopoly, it ends up extracting all of the economic rent.
} 
$2(n-2) /(n+1)=16 / 11$, the corner solution occurs; the information seller would sell to 9 of the 10 firms. If the information were sold to everyone, it would be useless for rivaling strategy. To strategically exploit its rivaling clients, the information seller would not sell the information to everyone.

Proposition 2 summarizes the comparative static analysis of the information seller's equilibrium strategy.

Proposition 2. Assuming interior solutions with $(t / R)<2(n-2) /(n+1)$ and $n>2$, then

(i) the equilibrium information price decreases with the producers' information technology and decreases with the total number of potential clients; the effect of perceived environment uncertainty on equilibrium information price is ambiguous;

(ii) the optimal target number of contracts increases with the producers' information technology, increases with the perceived environment uncertainty, and increases with the total number of potential clients;

(iii) the equilibrium profits for the information seller decreases with the producers' information technology, increases with the perceived environment uncertainty, and decreases with the total number of potential clients.

Part (i) of Proposition 2 is a direct corollary of Lemma 1 and shares similar interpretations. ${ }^{18}$

\section{Welfare implication of the information market}

Eq. (6) shows that producers' reservation price on external information is always positive. The following proposition shows that information selling generates economic externality in the product market and creates deadweight loss to the producers. ${ }^{19}$

Proposition 3. The existence of monopolistic information selling incurs an information deadweight loss to production firms. The loss to an individual producer, $D L$, is

$$
\mathrm{DL}=\frac{4[(n+1) t+R(k+2)](t+R) k t}{[(n+1) t+2 R]^{2}[(n+1) t+2 R(k+1)]^{2} b} .
$$

The deadweight loss in Eq. (9) results from the rent-seeking behavior of the information monopolist. That is, to maximize profit, the monopolist may not sell information to all the production firms. The uninformed firms make their production decision on their imprecise private signals, which will cause efficiency losses in the market as a whole. The total producers' loss to the industry, IDL, is then equal to $n \times$ DL. A producer's information purchase improves its own expected profit but reduces the expected

\footnotetext{
18 In Proof of Proposition 2, we observe a critical level of the relative information precision ratio $(t / R)=2 /(n-2)$; below that, the perceived environment uncertainty $R$ has a positive impact on the equilibrium information price, and above that, a negative impact.

19 Examples that information hurts the players in games of incomplete information can also be found in Chang and Lee (1992) and Kamien, Tauman, and Zamir (1990).
} 
profit of all other firms. Hence, all uninformed firms would be worse off with the presence of the information market. Inasmuch as the information seller is a natural monopoly who knows all its clients' reservation prices, the private benefit of information purchase would be totally extracted by the discriminatory fee structure. The informed firm, who shares the social cost of economic externality without the private benefit of information purchase, should be worse off too.

An inspection of Eq. (9) yields some insights as to the size of the deadweight loss. As the product market becomes more competitive, that is, $n$ gets larger, the level of deadweight loss becomes smaller because the strategic importance of information will be less significant in a competitive setting. When the quality of in-house information technology is improved, that is, $t$ is larger, then the deadweight loss will be smaller because the uninformed firms can predict the uncertain demand better and thus reduce the overall uncertainty of the market. Similar results can be said when the perceived environment uncertainty is reduced, that is, $R$ becomes larger.

The existence of information selling also has impact on the expected equilibrium price in the product market and thus on the consumers surplus. The purchased information enables producers to reduce their uncertainty and to improve their production planning. This helps to reduce the volatility in the aggregate output and to smoothen the variation in the equilibrium product price. Hence, consumers face less uncertainty in consumption decisions and are better off as a result.

Proposition 4. In an oligopoly with symmetric information technology,

(i) the existence of an information market does not affect the expected equilibrium price of the product but decreases its variance;

(ii) the existence of an information market always improves expected consumers' surplus.

The next proposition not only combines the welfare considerations for both the producers and consumers in equilibrium but also takes into account the fixed information cost.

Proposition 5. Assuming interior solutions, in a symmetric oligopoly with an information selling monopoly,

(i) if the fixed information cost for the information seller is sufficiently small, the existence of information selling has a positive total social value in equilibrium;

(ii) if $(t / R)$ is large enough, then there exists a fixed information cost that makes the service of information monopoly a private good but a social waste.

Monopolistic information selling is a social good when production firms' information precision $(t)$ are low and the perceived uncertainty of the economic environment $(R)$ is high. However, the strategic consideration can lead rivaling producers to overspending on information acquisition. When the relative quality of producers' information technology is high, the information seller's service is not very socially valuable. The producers' willingness to pay for this wasteful service simply arises from Cournot rivalry. The information monopoly earns its living from playing its rivaling clients against each other. Hence, the information seller is a social nuisance.

When the firm's information technology precision is relatively high and/or the economic environment is uncertain, the information monopoly would be a "necessary evil" - the society member may resent its 
economic exploitation but would be worse off without its existence. However, when the economic environment is relatively free of random shocks, the economic policy should restrain the activities of a costly information monopoly in an oligopolistic product market.

\section{Concluding remarks}

This paper is an attempt to understand the strategic role of information transaction and the interaction between the information and product markets. We derive equilibrium conditions for these two markets. We conclude that a producer's information acquisition decision depends on its in-house research abilities and the information decisions of its rivals. Although the marketing information is a private good to each individual production firm, the presence of an information market actually makes all production firms worse off. However, consumers always find information selling beneficial.

The model of the three-stage Bayesian-Cournot game can be applied to the transaction of other information, such as the selling of computer software, and management and accounting information systems. The monopolistic nature for providing external information service and the oligopolistic nature for industrial information users demand a model of analysis like ours. Information acquisition and processing become an increasingly crucial activity of modern business and management. It is well recognized that information plays an important strategic role in business rivalry. Our analysis provides a formal attempt to understand this important issue.

\section{Appendix A}

A. Proof of Proposition 1: From Lemma 1, the demand for information contracts is strictly downward sloping. Therefore, the information seller can use either the price or the number of contracts as its decision variable. For convenience, we assume the information seller uses $k$ as the decision variable. Given the producer's strategy in Eq. (3) and the fact that the information seller has all the bargaining power, the information seller's best reply is to set the information price so that $\alpha^{*}(k)=v(k), \forall k<n$. Hence, the information seller's profit (net of information costs) is defined as

$$
k v(k)=\frac{k(3 t+4 R)}{[(n+1) t+2 R(k+1)]^{2} b}, \quad \text { if } k<(n-1) .
$$

Differentiate the total profit in Eq. (A1) with respect to $k$ yields

$$
\frac{\partial[k v(k)]}{\partial k}=\frac{(3 t+4 R)[(n+1) t+2 R-2 k R]}{[(n+1) t+2 R(k+1)]^{3} b} .
$$

Setting Eq. (A2) to zero and solving for $k$, one obtains

$$
k^{*}=1+\frac{(n+1) t}{2 R},
$$

and $k^{*}<(n-1)$ implies that $t / R<2(n-2) / n$. 
The second derivative of the total profit with respect to $k$ is

$$
\frac{\partial^{2}[k v(k)]}{\partial k^{2}}=-\frac{4 R(3 t+4 R)[(n+1) t+2 R]}{[(n+1) t+2 R(k+1)]^{4} b}<0 .
$$

The second order condition implies that $k^{*}$ gives rise to the unique maximum information profit.

If $t / R \geq 2(n-2) / n$, then corner solutions $k^{*}=(n-1)$ with $\alpha^{*}(n-1)=v(n-1)$, or $k^{*}=n$ with $\alpha^{*}(n)=$ $\hat{v}(n)$, may occur. Comparing the profits of these two equilibriums, we have

$$
(n-1) v(n-1)-n \hat{v}(n)=\frac{(n-3)(n+1) t+4 R\left(n^{2}-n-1\right)}{(n+1)[(n+1) t+2 n R]^{2} b}
$$

The difference above is positive for $n \geq 3$ and is negative for $t / R \geq 4 / 3$ and $n=2$. Therefore, the corner solution $k^{*}=n$ with $\alpha^{*}(n)=\hat{v}(n)$ prevails if $t / R \geq 4 / 3$ and $n=2$. Otherwise, the equilibrium is $k^{*}=n-1$ with $\alpha^{*}(n-1)=v(n-1)$. The optimal profits can be obtained by substitution.

B. Proof of Proposition 2: The equilibrium information price $v\left(k^{*}\right)$ is obtained by substituting $k^{*}$ into Eq. (6):

$$
v\left(k^{*}\right)=\frac{3 t+4 R}{4[(n+1) t+2 R]^{2} b} .
$$

Partially differentiate $v\left(k^{*}\right)$ with respect to $t$ and $R$ yields:

$$
\begin{aligned}
\frac{\partial v\left(k^{*}\right)}{\partial t} & =-\frac{3(n+1) t+2(4 n+1) R}{4[(n+1) t+2 R]^{3} b}<0, \frac{\partial v\left(k^{*}\right)}{\partial R}=\frac{(n-2) t-2 R}{[(n+1) t+2 R]^{3} b} \\
& = \begin{cases}\leq 0, & \text { if } \frac{t}{R} \leq \frac{2}{(n-2)}, \\
>0, & \text { if } \frac{t}{R}>\frac{2}{(n-2)} .\end{cases}
\end{aligned}
$$

Also, it is obvious that $\partial v\left(k^{*}\right) / \partial n<0$.

Given $(t / R)<2(n-2) /(n+1), k^{*}$ is a function of parameters $t, R$, and $n$. Partially differentiate $k^{*}$ with respect to these parameter yields

$$
\frac{\partial k^{*}}{\partial t}=\frac{n+1}{2 R}>0, \frac{\partial k^{*}}{\partial R}=-\frac{(n+1) t}{2 R^{2}}<0, \frac{\partial k^{*}}{\partial n}=t>0 .
$$

The equilibrium profit for the information seller is

$$
k^{*} v\left(k^{*}\right)=\frac{3 t+4 R}{8[(n+1) t+2 R] b R} .
$$


Therefore, partial differentiation yields

$$
\frac{\partial\left[k^{*} v\left(k^{*}\right)\right]}{\partial t}=\frac{1-2 n}{4[(n+1) t+2 R]^{2} b}<0, \frac{\partial\left[k^{*} v\left(k^{*}\right)\right]}{\partial R}=-\frac{3(n+1) t^{2}+4 R(3 t+2 R)}{8[(n+1) t+2 R]^{2} b R^{2}}<0
$$

Again, it is easy to see that $\partial\left[k^{*} v\left(k^{*}\right)\right] / \partial n<0$.

C. Proof of Proposition 3: Recall that $\Pi_{i}(k, 1)$ and $\Pi_{i}(k, 0)$ are respectively the ex ante expected profit function for the informed and the uninformed firms. Let $\Pi_{i}(0,0)$ be the ex ante expected profit function for a typical firm if there is no information market. The loss to an uninformed firm due to the existence of the information selling is the difference between the ex ante expected profit with information selling and the ex ante expected profit without information selling:

$$
\Pi_{i}(0,0)-\Pi_{i}(k, 0)=\frac{4[(n+1) t+R(k+2)](t+R) k t}{[(n+1) t+2 R]^{2}[(n+1) t+2 R(k+1)]^{2} b} .
$$

On the other hand, the loss to the informed firm is the same difference in ex ante expected profits plus the price of the information contract:

$$
\Pi_{i}(0,0)-\left[\Pi_{i}(k, 1)-v(k)\right]=\frac{4[(n+1) t+R(k+2)](t+R) k t}{[(n+1) t+2 R]^{2}[(n+1) t+2 R(k+1)]^{2} b} .
$$

Hence, every individual firm, regardless whether informed or not, suffers the same amount of welfare loss due to the information selling.

D. Proof of Proposition 4: Let superscripts $I$ and $N$ respectively denote the product market equilibrium with or without the information market.

(i) Without the information market, the equilibrium product price is

$$
\begin{aligned}
P^{N} & =a+\theta-b \sum_{i=1}^{n} q_{i}^{N} \\
& =a+\theta-\frac{n a}{(n+1) b}-\frac{t}{[(n+1) t+2 R] b} \sum_{i=1}^{n} y_{i} .
\end{aligned}
$$

So, the mean and variance of price without the information market are

$$
\begin{aligned}
E\left(P^{N}\right) & =\frac{a}{(n+1) b}, \operatorname{VAR}\left(P^{N}\right)=\operatorname{VAR}(\theta)+\frac{t^{2} \operatorname{VAR}\left(y_{i}\right)}{[(n+1) t+2 R]^{2} b^{2}}-\frac{2 t \operatorname{COV}\left(\theta, \sum_{i=0}^{n} y_{i}\right)}{[(n+1) t+2 R] b} \\
& =\frac{1}{R}-\frac{n t[(n+2) t+3 R]}{[(n+1) t+2 R]^{2} b^{2} R} .
\end{aligned}
$$


With $k$ information contracts, then the equilibrium product price is

$$
\begin{aligned}
P^{I} & =a+\theta-b \sum_{i=1}^{n} q_{i}^{I} \\
& =a+\theta-\frac{n a}{(n+1) b}-\frac{k(t+2 R) \theta+t \sum_{j \in J} y_{j}}{[(n+1) t+2 R(k+1)] b},
\end{aligned}
$$

where $J$ is the set of all uninformed firms, that is, $J=\left\{j \mid \tau_{j}^{*}=0\right\}$. The expectation and variance of price are

$$
\begin{aligned}
E\left(P^{I}\right)= & \frac{a}{(n+1) b}, \\
\operatorname{VAR}\left(P^{I}\right) & =\operatorname{VAR}(\theta)+\frac{\operatorname{VAR}\left[k(t+2 R) \theta+\sum_{j \in J} y_{j}\right]}{[(n+1) t+2 R(k+1)]^{2} b^{2}}-\frac{2 \operatorname{COV}\left[\theta, k(t+2 R) \theta+t \sum_{j \in J} y_{j}\right]}{[(n+1) t+2 R(k+1)] b} \\
& =\frac{1}{R}-\frac{n(n+2) t^{2}+[(5+4 n) k+3 n] R t+4 k(k+2 R) R^{2}}{[(n+1) t+2 R(k+1)]^{2} b^{2} R} .
\end{aligned}
$$

Comparing the two variances, $\left[\operatorname{VAR}\left(P^{N}\right)-\operatorname{VAR}\left(P^{I}\right)\right]$ is:

$$
\frac{4 K[(n+1) t+(k+2) R]\left[(t+2 R)^{2}+n R t\right]+k[(n+1) t+2 R]^{2} t}{[(n+1) t+2 R]^{2}[(n+1) t+2 R(k+1)]^{2} b^{2}}>0 .
$$

(ii) Let $Q^{*}$ be the equilibrium aggregate output in the product market, then the expected consumer surplus (ECS) is

$$
\mathrm{ECS}=\frac{1}{2} E\left(b Q^{* 2}\right)=\frac{b}{2} E\left[E\left(Q^{*}\right)^{2}+\operatorname{VAR}\left(Q^{*}\right)\right]
$$

Hence, the expected consumer surplus without an information seller, $\mathrm{ECS}^{N}$, is

$$
\mathrm{ECS}^{N}=\frac{(n a)^{2}}{2(n+1)^{2} b}+\frac{n(R+n t) t}{2[(n+1) t+2 R]^{2} b R} .
$$


Similarly, the expected consumer surplus with an information seller selling $k$ information contracts is

$$
\operatorname{ECS}^{I}=\frac{(n a)^{2}}{2(n+1)^{2} b}+\frac{k^{2}(t+2 R)^{2}+(n-k)[(R+n t+k(t+4 R)]}{2[(n+1) t+2 R(k+1)]^{2} b R} .
$$

Therefore, the increment in expected consumer surplus (IECS $=\mathrm{ECS}^{I}-\mathrm{ECS}^{N}$ ) due to the existence of an information market is

$$
\frac{16 k^{2} R^{3}+\left\{4\left[3 n^{2}+(2 k+1) n+k\right]-1\right\} k R t^{2}+4(5 n+3 k) k R^{2} t+\left(3 n^{2}+2 n-1\right) k t^{3}}{2[(n+1) t+2 R(k+1)]^{2}[(n+1) t+2 R]^{2} b}
$$

It is obvious that IECS is positive.

E. Proof of Proposition 5: Define the business surplus (BS) as the information seller's total proceeds from the equilibrium information selling (PIS) net of the fixed information costs (FIC) and the production firms' aggregate information deadweight loss (IDL) in equilibrium. Assuming interior equilibrium, PIS is $k^{*} v\left(k^{*}\right)$ defined in Proposition 1. IDL is obtained from substituting $k^{*}$ into the total deadweight loss defined in Proposition 3:

$$
\mathrm{IDL}=\frac{3 n t(t+R)}{4[(n+1) t+2 R]^{2} b R}
$$

Hence,

$$
\mathrm{BS}=\mathrm{PIS}-\mathrm{FIC}-\mathrm{IDL}=\frac{(3 t+4 R)(t+2 R)-n(3 t+2 R)}{8[(n+1) t+2 R]^{2} b R}-\mathrm{FIC} .
$$

By Eq. (A5), the increment in expected consumer surplus in equilibrium (IECS*) is

$$
\mathrm{IECS}^{*}=\frac{(t+2 R)(t+4 R)+n t(7 t+10 R)}{16[(n+1) t+2 R]^{2} b R} .
$$

Lastly, the total social welfare (TSW) is defined as

$$
\mathrm{TSW}=\mathrm{BS}+\mathrm{IECS}^{*}=\frac{(t+2 R)(7 t+12 R)+n t(t+6 R)}{16[(n+1) t+2 R]^{2} b R}-\mathrm{FIC}
$$

It is obvious that TSW is positive if FIC is small enough.

(ii) The total social welfare is formally defined as

$$
\mathrm{TSW}=\mathrm{BS}+\mathrm{IECS}^{*}=\mathrm{PIS}-\mathrm{FIC}+\mathrm{IECS}^{*}-\mathrm{IDL} .
$$


A necessary condition for TSW to be negative but the information seller's equilibrium profits positive is IECS*<IDL. From Eqs. (A5) and (A6),we have

$$
\begin{aligned}
& \text { IECS* }- \text { IDL }=\frac{(t+2 R)(t+4 R)-n t(5 t+2 R)}{16[(n+1) t+2 R]^{2} b R}<0, \quad \text { iff }-(5 n-1) \frac{t^{2}}{R^{2}}+2(3-n) \frac{t}{R}+8<0, \\
& \text { iff } \frac{t}{R}>\frac{2(3-n)+\sqrt{(6-2 n)^{2}+32(5 n-1)}}{2(5 n-1)} .
\end{aligned}
$$

\section{Appendix B}

This appendix extends the model into a more general case with asymmetric information technologies for production firms. We assume that firms may be ranked according to their information technologies: $t_{1} \leq t_{2} \leq t_{3} \leq \ldots \leq t_{n}$.

In Decision III, given $\tau, \theta$, and $y=\left(y_{1}, y_{2}, \ldots, y_{n}\right)$, there exists a unique equilibrium with the following equilibrium strategy

$$
q_{i}^{*}= \begin{cases}\frac{a}{(n+1) b}+\frac{1}{\left(1+\sum_{j=1}^{n} \lambda_{j}\right) b R} \theta, & \text { if } \tau_{i}=1, \\ \frac{a}{(n+1) b}+\frac{t_{i}}{\left(1+\sum_{j=1}^{n} \hat{\lambda}_{j}\right)\left(t_{i}+2 R\right) b R} & \text { if } \tau_{i}=0,\end{cases}
$$

where $\lambda_{j}=t_{j} /\left(t_{j}+2 R\right)$. Let $\tau_{-i}=\left(\tau_{1}, \tau_{2}, \ldots, \tau_{i-1}, \tau_{i+1}, \ldots, \tau_{\mathrm{n}}\right)$ and $\hat{\tau}_{i}$ be the $(n-1)$ tuple vector with $\hat{\tau}_{j}=\tau_{j}$, $\forall j \neq i$, and there exists an $m \neq i$ such that $\tau_{m}=0$ and $\hat{\tau}_{m}=1$. Redefine $\Pi_{i}\left(\tau_{-i}, \tau_{i}\right)$ as firm $i$ 's ex ante expected profit function if the information contracting in the market is represented by $\left(\tau_{-i}, \tau_{i}\right)$, then

$$
\begin{aligned}
& \Pi_{i}\left(\tau_{-i}, 1\right)=\frac{a^{2}}{(n+1)^{2} b}+\frac{1}{\left(1+\sum_{j=1}^{n} \lambda_{j}\right)^{2} b R} \\
& \Pi_{i}\left(\hat{\tau}_{-i}, 0\right)=\frac{a^{2}}{(n+1)^{2} b}+\frac{t_{i}\left(t_{i}+R\right)}{\left(1+\sum_{j=1}^{n} \hat{\lambda}_{j}\right)^{2}\left(t_{i}+2 R\right)^{2} b R}
\end{aligned}
$$

Hence, the value of information to firm $i$, given $\tau_{-i}$ and $\hat{\tau}_{-i}$, is

$$
v_{i}\left(\tau_{-i}, \hat{\tau}_{-i}\right)=\Pi_{i}\left(\tau_{-i}, 1\right)-\Pi_{i}\left(\hat{\tau}_{-i}, 0\right) .
$$


Note that from Eq. (B1) and the definition of $v_{i}(\cdot)$, we see that the value of information to firm $i$ depends not only on the number of the informed firms but also on the information technologies of all the uninformed firms. Suppose the information seller wants to sell information to $k$ firms, then the seller has to compare $n ! /[k !(n-k) !]$ different values of information to make the optimal information-selling decision. Due to the complexity of this decision-making process, an analytical equilibrium solution as the one obtained in Proposition 1 is not immediately available. Instead, numerical simulations are conducted to gain understanding of the nature of the equilibrium. The simulation results are reported in Chang and Lee (1994). Some of the major findings are summarized below.

In general, there exists an equilibrium in Decision I of the game. The information seller still faces a downward sloping demand curve in the information market. In equilibrium, the seller identifies those firms who value the information most and set the price of the contract to a particular firm equal to the firm's value of information. Inasmuch as the information technologies are asymmetric, the information prices charged to different firms are distinct. Thus, we have a perfect discriminative information seller if the seller knows the vector $t=\left(t_{1}, t_{2}, \ldots, t_{n}\right){ }^{20}$

One interesting result is that the information seller always sells contracts to firms with the highest information technologies in equilibrium. That is, if it is optimal selling to $k$ firms, the seller chooses firm $(n-k+1)$ through firm $n$. This result may be explained by the strategy-enhancing effect of the firm. In the product market, the informed firm enjoys an informational benefit because it can use its superior signal to take advantage of the uninformed. Firm $n$, having information technology more advanced than any other firms, will enjoy the greatest advantage if it becomes informed. Therefore, firm $n$ has the greatest value of information among all firms should the information seller intend to sell only one contract. The same logic applies if the seller wants to sell more than one contract - it always chooses the firms with higher $t_{i}$ 's.

In addition, all the comparative static results in Proposition 2 still hold in the asymmetric case. For example, other things being equal, if all $t_{i}$ 's are small in value, then in equilibrium, the seller chooses to sell only to firm $n$. The number of contracts sold increases with the values of $t_{i}$ 's and decreases with $R$. Finally, as $t_{i}$ 's become large enough, the seller will sell to $(n-1)$ firms - all but Firm 1 .

\section{References}

Admati, A. R., \& Pfleiderer, P. (1986). A monopolistic market for information. Journal of Economic Theory, $39,400-438$. Admati, A. R., \& Pfleiderer, P. (1990). Direct and indirect sale of information. Econometrica, 58, 901-928.

Cason, T. N., \& Mason, C. F. (1999). Information sharing and tacit collusion in laboratory duopoly markets. Economic Inquiry, $37,258-281$.

Chang, C., \& Lee, C. J. (1992). Information acquisition as business strategy. Southern Economic Journal, 58, $750-761$.

Chang, C., \& Lee, C. J. (1994). Optimal pricing strategy in marketing research consulting. International Economic Review, 35, $463-478$.

Clarke, R. (1983). Collusion and incentives for information sharing. Bell Journal of Economics, 14, $383-394$.

Degroot, M. (1970). Optimal statistical decisions. New York: McGraw Hill.

Doyle, M. P., \& Snyder, C. M. (1999). Information sharing and competition in the motor vehicle industry. Journal of Political Economy, 107, 1326-1364.

${ }^{20}$ If the information seller cannot identify the information precision of each individual firm, then the seller will no longer be able to price discriminate. Instead, the seller will set an average price and let firms self-select. In the equilibrium, all firms with values of information higher than the price will purchase the contract. 
Fried, D. (1984). Incentives for information production and disclosure in duopoly environment. Quarterly Journal of Economics, 99(2), 367-381.

Gal-Or, E. (1985). Information sharing in oligopoly. Econometrica, 53, 329-343.

Harsanyi, J. (1967). Games with incomplete information played by Bayesian players. Management Science, 14, 159-182, $320-334,486-502$.

Hirshleifer, J., \& Riley, J. (1992). The analytics of uncertainty and information. Cambridge, UK: Cambridge University Press.

Honomichl, J. J. (1989). Special report: Research business review, 1989. Advertising Age, S1-S20.

Hwang, H. (1993). Optimal information acquisition for heterogenous duopoly firms. Journal of Economic Theory, 59, $385-402$.

Jin, J. Y. (1994). Information sharing through sales report. Journal of Industrial Economics, 42, 323-333.

Jin, J. Y. (2000). A comment on a general model of information sharing in oligopoly. Journal of Economic Theory, 93, $144-145$.

Kamien, M., \& Tauman, Y. (1986). Fees versus royalties and the private value of patent. Quarterly Journal of Economics, 101, 471-491.

Kamien, M., Tauman, Y., \& Zamir, S. (1990). On the value of information in a strategic conflict. Games and Economic Behavior, 2, 129-153.

Kao, J. L., \& Hugres, J. S. (1993). Note on risk aversion and sharing of firm-specific information in oligopoly. Journal of Industrial Economics, XLI, 103-112.

Katz, M. L., \& Shapiro, C. (1986). How to license intangible property. Quarterly Journal of Economics, 567-589.

Li, L. (1985). Cournot oligopoly with information sharing. Rand Journal of Economics, 16, 521-536.

Li, L., McKelvey, R., \& Page, T. (1987). Optimal research for Cournot oligopolists. Journal of Economic Theory, 42, 140-166.

McLean, J. (1990). Consultants and consulting organization directory: A reference guide to concerns and individuals engaged in consultation for business, industry, and government, Vol. 1 (10th ed.). Detroit, MI: Gale Research.

Novshek, W., \& Sonnenschein, H. (1982). Fulfilled expectations Cournot duopoly with information acquisition and release. Bell Journal of Economics, 13, 214-218.

Ponssard, J. P. (1976). On the concept of the value of information in competitive situations. Management Science, 22, $739-747$.

Ponssard, J. P. (1979). The strategies role of information on the demand function in an oligopolistic market. Management Science, 25, 243-250.

Raith, M. (1996). A general model of information sharing in oligopoly. Journal of Economic Theory, 71, 260-288.

Shapiro, C. (1986). Exchange of cost information in oligopoly. Review of Economic Studies, 53, 433-446.

Vives, X. (1984). Duopoly information equilibrium: Cournot and Bertrand. Journal of Economic Theory, 34, 71-94.

Vives, X. (1988). Aggregation of information in large Cournot markets. Econometrica, 56, 851-876.

Ziv, A. (1993). Information sharing in oligopoly: The truth-telling problem. Rand Journal of Economics, 24, 455-465. 